\title{
Spontaneous loss and transfer of plasmid-mediated K21 antigen synthesis in Klebsiella pneumoniae
}

\author{
JG BARR
}

From the Department of Clinical Bacteriology, Royal Victoria Hospital, Belfast BT12 6BA, Northern Ireland

SUMMARY Five epidemiologically related urine isolates of Klebsiella pneumoniae (sensu lato), $\frac{\widehat{O}}{\mathrm{O}}$ capsular serotype $\mathrm{K} 21$, may spontaneously lose the ability to synthesise K21 antigen in vitro and in ${ }_{\omega}$ vivo. Another four isolates of $K$. pneumoniae $\mathrm{K}_{21+}$, epidemiologically unrelated to the other five, did $\stackrel{+}{+}_{+}^{+}$ not exhibit this effect. Elimination of the ability to synthesise K21 antigen may be enhanced by



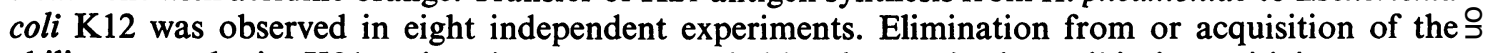
ability to synthesise K21 antigen is not accompanied by changes in the antibiotic sensitivity patterns $\vec{\longrightarrow}$ or biochemical characteristics of bacteria.

During 1978 a cluster of isolates of Klebsiella pneumoniae (sensu lato), capsular type $\mathrm{K} 21$, was detected in an orthopaedic ward during routine surveillance of Gram-negative bacterial colonisation and infection. ${ }^{1}$ Each of five catheter specimens of urine from this unit yielded two morphologically distinguishable bacterial colonies, which both proved to be K. pneumoniae (sensu lato) isolates of the same biotype when examined by conventional means. The occurrence of a mixed growth of different genera or species, or even of the same species, from urine of long-term catheterised patients is in itself not unusual and may result from sequential colonisation by different bacteria. However, the occurrence of two isolates of the same Klebsiella species and biotype in each of five epidemiologically related specimens suggested that another more plausible interpretation was likely.

Subsequently, pairs of isolates from single urine specimens were shown to differ in their production of capsular antigen K21. Further investigations were carried out to determine whether the determinants for K21 antigen synthesis were carried on a transmissible plasmid.

\section{Material and methods}

CULTURES

Each of five catheter urine specimens (U53, U95, U106, U124, U214) yielded two klebsiella isolates

Accepted for publication 16 June 1980 distinguishable by colony morphology. In each case $\stackrel{\infty}{-}$ a large mucoid colony type (U53/1, U95/1, etc) and a smaller non-mucoid colony type (U53/2, U95/2, ํํำ etc) could be recognised. Rifampicin-resistant, nonmucoid klebsiella strains for use in transfer experiments were derived from klebsiella isolates U53/2 $\stackrel{\circ}{\square}$ and $U 95 / 2$ by passage in rifampicin broth. Rifam- $\stackrel{2}{\vec{F}}$ picin-resistant mucoid klebsiella strains were selected $\frac{3}{3}$ from klebsiella isolates $U 53 / 1$ and $U 95 / 1$ by the same method.

DONOR STRAINS

Five mucoid isolates of $K$. pneumoniae $\mathrm{K} 21+$ (U53, U95, U106, U124, U214) were used as donor strains.

RECIPIENT STRAINS

A spontaneous mutant of Escherichia coli $\mathrm{K} 12$,윽 resistant to rifampicin and naladixic acid, was kindly $\supset$ supplied by $\mathrm{Dr} \mathrm{H}$ Williams Smith, of Houghton Poultry Research Station. Either a smooth or rough colony strain, derived from this culture, served as $\sigma$ recipient in most transfer experiments. The rough ${ }_{0}$ strain (AP1 20E; 1044 512) could be differentiated from the smooth strain (AP1 20E; 5044 512) by the absence in the former of lysine decarboxylaseo activity.

In some transfer experiments, rifampicin-resistant, $\stackrel{\mathscr{\rho}}{?}$ non-mucoid klebsiella strains U53/2 and U95/2 O served as recipients.

BIOCHEMICAL TYPING

Klebsiella isolates were biotyped by the methods of 434 
Barr ${ }^{1}$ and Rennie and Duncan, ${ }^{2}$ and by a commercially available system (AP1-20E). ${ }^{3}$ Another commercially available system, AP1-50E, includes 50 biochemical tests, the majority relating to the fermentation of different carbon substrates. The biochemical identity of some strains was confirmed using this system.

The method of Rennie and Duncan ${ }^{2}$ included the following tests: indole production, acetoin production, citrate utilisation, lactose and sucrose fermentation, malonate and gluconate utilisation, dulcitol fermentation, lysine and ornithine decarboxylase, and urease activity. Positive and negative results were computed to yield a three-digit code for each biotype.

Biochemical typing was also carried out by a method $^{1}$ which discriminates between strains on the basis of acid accumulation from the metabolism of five substrates (xylose, glucose, lactose, inositol, glycerol), each at two concentrations. For each substrate, at two concentrations, three results were possible: test results positive at both concentrations, denoted ' 2 '; test results positive only at the higher concentration, denoted ' 1 '; and test results negative at both concentrations, ' 0 '. Results were recorded in the following order, viz, glycerol, inositol, lactose, glucose, and xylose. This yielded for each strain a five-digit code.

\section{CAPSULAR SEROTYPING}

Capsular serotyping was carried out on cultures grown for 18 hours at $37^{\circ} \mathrm{C}$ on Worfel-Ferguson agar and sensitivity test agar (DST agar; Oxoid) supplemented with $5 \%$ lysed blood. Sensitivity test agar supported the production of more capsular polysaccharide by $E$. coli transconjugants than other media.

Slide agglutination tests and Quellung reactions were carried out as described by Casewell ${ }^{4}$ except that K21 serum (Difco) was used neat, as well as in a $1 / 8$ dilution. The serum was used either absorbed or unabsorbed, depending on the culture being examined. Counter immunoelectrophoresis (CIE) was kindly carried out at Coventry Public Health Laboratory by the methods described by Palfreyman. ${ }^{5}$ Some Quellung reactions were also confirmed by that laboratory.

\section{ELIMINATION OF K21 ANTIGEN SYNTHESIS}

Nutrient broth (Oxoid No 2) was inoculated with single colonies of either rifampicin-sensitive or rifampicin-resistant mucoid cultures of klebsiella strains U53/1 or U95/1. After 16 hours' incubation at $37^{\circ} \mathrm{C}$, cultures were diluted to $10^{4}$ cells per $\mathrm{ml}$ in nutrient broth, with or without acridine orange $(20$ $\mathrm{mg} / \mathrm{l})$, and incubated for a further 16 hours at $37^{\circ} \mathrm{C}$.
Appropriate dilutions were plated out to obtain nonconfluent growth on MacConkey agar, with or without rifampicin $(150 \mathrm{mg} / \mathrm{l})$, and colonies were selected for study on the basis of colonial morphology and colour.

\section{MATING PROCEDURES}

Small amounts $(0.5 \mathrm{ml})$ of 3-hour broth cultures of the donor and recipient cultures were mixed into $5 \mathrm{ml}$ of fresh nutrient broth (Nutrient Broth; No 2 Oxoid) and grown together for 16 hours. Small volumes $(0 \cdot 1 \mathrm{ml})$ of an appropriate dilution $\left(10^{-3}\right)$ were plated out on MacConkey agar containing rifampicin $(150 \mathrm{mg} / \mathrm{l})$, to which the recipient was resistant. This normally yielded between 150 and 400 colonies, from which several $\mathrm{K} 21+$ transconjugant colonies could be selected for purification, capsular serotyping, and biochemical typing on the basis of colonial morphology.

Pure broth cultures of donor and recipient strains were treated in the same way and served as controls. Colonies were selected at random, from recipient control plates, for agglutination tests.

\section{ANTIBIOTIC SENSITIVITY TESTS}

Antibiotic sensitivity testing was carried out by a comparative method ${ }^{6}$ using sensitivity test agar (DST agar; Oxoid) supplemented with $5 \%$ lysed blood.

Sensitivity to the following antibiotics was determined: nitrofurantoin (NR), gentamicin (G), kanamycin $(K)$, cephalothin (KF), tetracycline $(T)$, sulphamethoxazole (S), trimethoprim (W), ampicillin (A), and naladixic acid (NA).

\section{Results}

ORIGIN AND RECOGNITION OF MIXED

KLEBSIELLA GROWTH IN URINE

Urine specimens from five catheterised patients in an orthopaedic ward yielded mixed growths of two distinguishable colony types, which were both identified by routine methods ${ }^{7}$ to be Klebsiella spp. In each case a large, raised, mucoid, pink colony, 3-5 $\mathrm{mm}$ in diameter, could be distinguished from a flat, non-mucoid, red colony of 1-2 $\mathrm{mm}$ in diameter on MacConkey agar. On routine subculture the smaller non-mucoid colony remained pure in cultural characteristics. Repeated subculture of the mucoid colony invariably yielded a small number of colonies of the other type.

An environmental swab, prompted by an epidemiological investigation in the same ward at a later date, also yielded a mixture of the two colony types. 
CHARACTERISTICS OF MUCOID AND

NON-MUCOID KLEBSIELLA STRAINS

The biochemical type, serotype, and antibiotic sensitivity patterns of mucoid and non-mucoid klebsiella isolates from five urine specimens are shown in Table 1.

Within each urine specimen, pairs of isolates were of the same conventional biotype $\mathrm{e}^{23}$ and had the same antibiotic sensitivity pattern. Pairs of isolates from single urine specimens were also identical in the wider range of tests provided by AP1-50E but could be distinguished by the biochemical typing method described by Barr ${ }^{1}$ and by the presence or absence of capsular antigen K21 (Table 1).

The ability to synthesise $\mathrm{K} 21$ antigen was lost without accompanying changes in conventional biochemical tests or antibiotic resistance pattern. This phenomenon was noted here in strains showing different resistance patterns; in two strains, U95/1 and $U 106 / 1$, the capacity for transfer of antibiotic resistance to $E$. coli $\mathrm{K} 12$ has previously been noted. ${ }^{1}$

\section{ELIMINATION OF ABILITY TO SYNTHESISE CAPSULAR ANTIGEN K21}

$\mathrm{K} 21^{-}$colonies were derived spontaneously at low rate from five epidemiologically related $K$. pneumoniae K21+ cultures U53/1, U95/1, U106/1, U124/1, and U214/1. Rifampicin-resistant cultures of U53/1 and $U 95 / 1$ spontaneously yielded rifampicin-resistant $\underline{0}$ $\mathrm{K} 21-^{-}$colonies at a similar rate. The culture of two selected mucoid strains U53/1 and U95/1 in broth containing acridine orange increased the yield of 0 $\mathrm{K} 21^{-}$colonies in each case (Table 2).

Four epidemiologically unrelated strains of $K$. pneumoniae $\mathrm{K}_{21+}^{+}$, isolated from other wards during $\mathbb{\Phi}$ the period of this study, did not spontaneously lose their ability to synthesise K21 antigen. Acridine orange did not induce elimination of capsule antigen $\vec{\circ}$ synthesis in these cultures.

\section{TRANSFER OF ABILITY TO SYNTHESISE K 21} ANTIGEN Spontaneously derived non-mucoid K21-cultures, $\stackrel{\omega}{\oplus}$ U53/2 and U95/2, rifampicin-resistant, served as recipients for the determinant of K21 antigen syn- $\vec{\perp}$ thesis with mucoid $\mathrm{K}_{21}{ }^{+}$strains of $K$. pneumoniae, $\mathrm{O}$ U53/1 and U95/1, as donors. No transfer could be detected when crosses were plated on rifampicin $>$ MacConkey agar. No colonies showed morpho-으․ logical or other phenotypic characteristics of the $\overrightarrow{-}$ $\mathrm{K} 21^{+}$parents, and no colonies tested agglutinated in $œ$ K21 serum.

In independent experiments, both smooth and rough forms of a spontaneous mutant of $E$. coli $\mathrm{K} 12$,

Table 1 Biochemical type, serotype, and antibiotic sensitivity patterns of mucoid and non-mucoid Klebsiella isolates

\begin{tabular}{|c|c|c|c|c|c|c|c|}
\hline \multirow{2}{*}{$\begin{array}{l}\text { Klebsiella } \\
\text { strain No. }\end{array}$} & \multicolumn{3}{|c|}{ Biochemical type } & \multicolumn{3}{|c|}{ Capsule serotype } & \multirow[t]{2}{*}{ Antibiotic resistance* } \\
\hline & $\begin{array}{l}\text { Rennie and } \\
\text { Duncan }\end{array}$ & $A P 1-20 E$ & $\begin{array}{l}\text { Substrate } \\
\text { metabolism }\end{array}$ & $\begin{array}{l}\text { Slide } \\
\text { agglutination }\end{array}$ & $\begin{array}{l}\text { Quellung } \\
\text { reaction }\end{array}$ & $C I E$ & \\
\hline $\begin{array}{l}U 53 / 1 \\
U 53 / 2 \\
U 95 / 1 \\
U 95 / 2 \\
U 106 / 1 \\
U 106 / 2 \\
U 124 / 1 \\
U 124 / 2 \\
U 214 / 1 \\
U 214 / 2\end{array}$ & $\begin{array}{l}112 \\
112 \\
112 \\
112 \\
112 \\
112 \\
112 \\
112 \\
112 \\
112\end{array}$ & $\begin{array}{lll}5 & 215773 \\
5 & 215773 \\
5 & 215773 \\
5 & 215773 \\
5 & 215773 \\
5 & 215773 \\
5 & 215773 \\
5 & 215773 \\
5 & 215773 \\
5 & 215773\end{array}$ & $\begin{array}{l}11222 \\
10212 \\
11222 \\
10212 \\
11222 \\
10212 \\
11222 \\
10212 \\
11222 \\
10212\end{array}$ & $\begin{array}{l}\text { K21 } \\
\text { NT } \\
\text { K21 } \\
\text { NT } \\
\text { K21 } \\
\text { NT } \\
\text { K21 } \\
\text { NT } \\
\text { K21 } \\
\text { NT }\end{array}$ & $\begin{array}{l}\text { K21 } \\
\text { NT } \\
\text { K21 } \\
\text { NT } \\
\text { K21 } \\
\text { NT } \\
\text { K21 } \\
\text { NT } \\
\text { K21 } \\
\text { NT }\end{array}$ & $\begin{array}{l}\text { K21 } \\
\text { NT } \\
\text { K21 } \\
\text { NT } \\
\text { K21 } \\
\text { NT } \\
\text { K21 } \\
\text { NT } \\
\text { ND } \\
\text { ND }\end{array}$ & 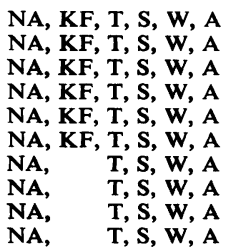 \\
\hline
\end{tabular}

NT $=$ not typable

ND $=$ not done

CIE = counterimmunoelectrophoresis

* See text for antibiotic abbreviations.

Table 2 Influence of acridine orange on elimination of synthesis of capsule antigen $\mathrm{K} 21$ from $\mathrm{K}$. pneumoniae

\begin{tabular}{|c|c|c|c|c|}
\hline \multirow[t]{2}{*}{ Strain } & \multirow{2}{*}{$\begin{array}{l}\text { Acridine orange } \\
(\mathrm{mg} / \mathrm{l})\end{array}$} & \multirow{2}{*}{$\begin{array}{l}\text { Number of } \\
\text { colonies examined }\end{array}$} & \multicolumn{2}{|c|}{ Yield of $\mathrm{K} 21^{-}$colonies } \\
\hline & & & Number & Per cent \\
\hline $\mathrm{U} 53 / 1$ & $\begin{array}{r}0 \\
20\end{array}$ & $\begin{array}{l}302 \\
255\end{array}$ & $\begin{array}{r}3 \\
30\end{array}$ & $\begin{array}{r}1 \\
12\end{array}$ \\
\hline U95/1 & 0 & 248 & 5 & 2 \\
\hline U1, U129, U3000, U326* & $\begin{array}{r}20 \\
0 \\
20\end{array}$ & $\begin{array}{r}119 \\
>150 \\
>150\end{array}$ & $\begin{array}{r}35 \\
0 \\
0\end{array}$ & $\begin{array}{r}19 \\
0 \\
0\end{array}$ \\
\hline
\end{tabular}

*Four $\mathrm{K21+}$ urine isolates of $K$. pneumoniae epidemiologically unrelated to U53, U95, etc. 
resistant to rifampicin and naladixic acid, served as a recipient for the determinant for $\mathrm{K} 21$ antigen synthesis. In matings with both these strains, five epidemiologically related and four unrelated mucoid $\mathrm{K} 21^{+}$strains of $K$. pneumoniae served as donors. However, only in matings between the smooth form of $E$. coli $\mathrm{K} 12$ and $K$. pneumoniae U53/1 and U95/1, and between the rough form of $E$. coli $\mathrm{K} 12$ and $K$. pneumoniae U53/1, could the presence of capsular antigen $\mathrm{K} 21$ in the transconjugant $E$. coli be demonstrated. The transfer of capsular antigen $\mathrm{K} 21$ was obtained independently on eight occasions. In all cases larger irregular, slightly mucoid colonies were detected in a non-confluent lawn of the recipient $E$. coli $\mathrm{K} 12$.

The percentage of mucoid $E$. coli colonies was about $1 \%$ in each of three matings between the smooth form of $E$. coli $\mathrm{K} 12$ and $K$. pneumoniae U53/1 and U95/1, and in two matings between the rough $E$. coli $\mathrm{K} 12$ and $K$. pneumoniae $\mathrm{U} 53 / 1$.

In crosses between the smooth form of $E$. coli $\mathrm{K} 12$ and $K$.pneumoniae, $\mathrm{K} 21$ antigen could be demonstrated by slide agglutination, Quellung reaction, and CIE (Table 3). Using the rough form of $E$. coli $\mathrm{K} 12$ as recipient, the presence of $\mathrm{K} 12$ antigen in selected $E$. coli transconjugants could be demonstrated by slide agglutination and Quellung reaction only, and not by CIE (Table 3). However, using the rough strain, transconjugants were less well capsulated, and the negative CIE result may reflect suboptimal concentrations of antigen in this case. Quellung reactions were also weak with these transconjugants.

Many Quellung reactions were confirmed, and CIE was carried out, at Coventry Public Health
Laboratory. Clearly positive Quellung reactions and CIE were normally obtained when cells were harvested from DST agar and when a lower dilution of antiserum than that normally used for routine CIE of klebsiella isolates was used.

Parent and transconjugant $E$. coli $\mathrm{K} 12$ strains could not be distinguished by biochemical typing by any of the three methods described (Table 3). The acquisition of the ability to synthesise $\mathrm{K} 21$ antigen was not accompanied in any case by the acquisition of antibiotic resistance, although a transfer of antibiotic resistance from $K$. pneumoniae U95/1 to $E$. coli $\mathrm{K} 12$ had previously been demonstrated. ${ }^{1}$

\section{Discussion}

The two colonial types isolated from each of five urines differ in production of capsular antigen K21. They do not, as shown in Table 1, differ in their antibiotic sensitivity pattern or in conventional biotype. Differences in biotype, as determined by differential substrate metabolism, ${ }^{1}$ have, however, been noted (Table 1), but these could be interpreted as due to phenotypic changes resulting from differences in uptake and metabolism of substrates and excretion of metabolic products by mucoid and non-mucoid strains. In a comparable situation, Ørskov and Ørskov ${ }^{8}$ reported that $E$. coli strains cured of $\mathrm{K} 88$ antigen synthesis could be recognised by a difference in colour, characteristic of $\mathrm{pH}$ value change on bromothymol blue lactose agar.

Mucoid klebsiella strains could be spontaneously cured of capsule antigen synthesis independently of changes in biochemical or antibiotic resistance

Table 3 Characteristics of $\mathrm{K}^{2} \mathrm{I}^{+}$donor $\mathrm{K}$. pneumoniae and recipient and transconjugant $\mathrm{E}$. coli $\mathrm{K} 12$ strains

\begin{tabular}{|c|c|c|c|c|c|c|c|}
\hline \multirow[t]{2}{*}{ Strain } & \multicolumn{3}{|c|}{ Biochemical type } & \multirow{2}{*}{$\begin{array}{l}\text { Antibiotic } \\
\text { resistance }\end{array}$} & \multicolumn{3}{|c|}{ Capsular serotype } \\
\hline & $\begin{array}{l}\text { Rennie and } \\
\text { Duncan" }\end{array}$ & $A P 1-20 E$ & $\begin{array}{l}\text { Substrate } \\
\text { metabolism }\end{array}$ & & $\begin{array}{l}\text { Slide } \\
\text { agglutination }\end{array}$ & $\begin{array}{l}\text { Quellung } \\
\text { reaction }\end{array}$ & $C I E$ \\
\hline \multicolumn{8}{|l|}{ Donor } \\
\hline $\begin{array}{l}\text { K. pneumoniae U53/1 } \\
\text { Recipient }\end{array}$ & 112 & 5215773 & 11222 & NA, KF, T, S, W, A & K21 & K21 & K21 \\
\hline $\begin{array}{l}\text { E. coli } \mathrm{K} 12 \text {, smooth } \\
\text { Transconjugant }\end{array}$ & 一 & 5044512 & 00122 & NA, RIF & NT & NT & NT \\
\hline $\begin{array}{l}\text { E. coli K12 } \\
\text { Donor }\end{array}$ & - & 5044512 & 00122 & NA, RIF & K21 & K21 & K21 \\
\hline $\begin{array}{l}\text { K. pneumoniae U95/1 } \\
\text { Recipient }\end{array}$ & 112 & 5215773 & 11222 & NA, KF, T, S, W, A & $\mathrm{K} 21$ & K21 & K21 \\
\hline $\begin{array}{l}E \text {. coli K12, smooth } \\
\text { Transconjugant }\end{array}$ & - & 5044512 & 00122 & NA, RIF & NT & NT & NT \\
\hline $\begin{array}{l}\text { E. coli K12 } \\
\text { Donor }\end{array}$ & 一 & 5044512 & 00122 & NA, RIF & K21 & $\mathbf{K} 21$ & K21 \\
\hline $\begin{array}{l}\text { K. pneumoniae U53/1 } \\
\text { Recipient }\end{array}$ & 112 & 5215773 & 11222 & NA, KF, T, S, W, A & $\mathbf{K} 21$ & $\mathbf{K} 21$ & K21 \\
\hline $\begin{array}{l}E \text {. coli K12, rough } \\
\text { Transconjugant }\end{array}$ & - & 1044512 & 00122 & NA, RIF & NT & NT & NT \\
\hline E. coli $\mathbf{K} 12$ & - & 1044512 & 00122 & NA, RIF & K21 & K21 & NT \\
\hline
\end{tabular}

* See text for antibiotic abbreviations.

$\mathrm{CIE}=$ counterimmunoelectrophoresis

NT $=$ not typable 
markers. Elimination of the ability to synthesise K21 antigen was enhanced by treatment with acridine orange, which advances the view that the determinants for K21 synthesis are borne on an extrachromosomal particle, a plasmid. This, however, is not necessarily a characteristic of $\mathrm{K} 21^{+}$strains of $K$. pneumoniae in general since other strains, epidemiologically unrelated to the ones considered here, did not show elimination of capsule antigen synthesis in the presence or absence of acridine orange.

The ability to synthesise K21 antigen may be transferred at low rate from mucoid $K$. pneumoniae strains to $E$. coli $\mathrm{K} 12$. The percentage of positive $\mathrm{K} 21{ }^{+} E$. coli $\mathrm{K} 12$ colonies was about $1 \%$ in each of the eight cases in which transfer occurred. Transfer to $\mathrm{K} 21^{-}$cultures of $K$. pneumoniae derived by spontaneous elimination of $\mathrm{K} 21$ antigen from mucoid

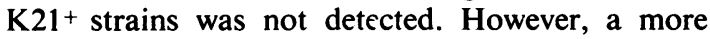
exhaustive examination of recipients for transconjugants, and the use of other klebsiella strains as recipients for $\mathrm{K} 21$ antigen synthesis, could be profitable.

It has been shown here that spontaneous loss of capsular antigen synthesis may occur in vivo and in vitro and may simulate mixed infection or colonisation in patients. In this laboratory, klebsiella isolates without capsule antigen synthesis are rarely encountered in pure growth in clinical specimens. Those that have been recorded have been epidemiologically unrelated to and of a different biochemical type from the $\mathrm{K}^{2} 1^{-}$and $\mathrm{K} 21^{+}$strains described in this paper. Indeed, non-capsulated strains $\mathrm{K}_{21}{ }^{-}$, of the biotype noted in the cultures described here, have been isolated only in mixtures in clinical specimens with the homologous $\mathrm{K} 21^{+}$strains, suggesting that it is unlikely that $\mathrm{K}^{2} 1^{-}$strains of this biochemical type are as effective colonisers as their capsulated counterparts.

This report establishes that transferable plasmidmediated K21 antigen synthesis may occur in $K$. pneumoniae (sensu lato). Further investigations may demonstrate that the determinant for capsule antigen K21 may be transmissible to other klebsiella strains as well as to $E$. coli $\mathrm{K} 12$. This would certainly be of interest, since in some series of klebsiella isolates ${ }^{9}$ capsular serotype $\mathrm{K} 21$ is prevalent. In a later investigation, ${ }^{10}$ capsular type $\mathrm{K} 21$ comprised $42.0 \%$ of klebsiella isolates derived from hospitals in the United Kingdom. This prevalence could possibly arise from transmission of the determinant for K21 antigen synthesis among klebsiella strains and/or by an especial ability of this serotype to colonise and infect patients.

I wish to thank Professor RR Gillies for constructive criticism of the paper, Miss L Stewart and Miss C Kelly for preparation of the text, and Dr PR Mortimer and Miss JM Palfreyman, Coventry Public Health Laboratory, for their assistance.

\section{References}

${ }^{1}$ Barr JG. Biotypes of Klebsiella pneumoniae (sensu lato) and Enterobacter aerogenes characterised by differential substrate metabolism: application of the technique. $J \mathrm{O}$ Clin Pathol 1979;32:935-43.

${ }^{2}$ Rennie RP, Duncan IBR. Combined biochemical and serological typing of clinical isolates of Klebsiella. Appl Microbiol 1974;28:534-9.

${ }^{3}$ Silva MDe, Rubin SJ. Multiple biotypes of Klebsiella $\vec{c}$ pneumoniae in single clinical specimens. J Clin Microbiol 1977;5:62-5.

4 Casewell MW. Experiences in the use of commercial antisera for the typing of Klebsiella species. J Clin Pathol $1972 ; 25: 734-7$.

${ }^{5}$ Palfreyman JM. Klebsiella serotyping by countercurrent immunoelectrophoresis. J Hyg Camb 1978;81:219-25.

${ }^{6}$ Stokes EJ, Waterworth PM. Antibiotic sensitivity tests by diffusion methods. Association of Clinical Pathologists, Broadsheet 55: (Revised December 1972).

' Barr JG, Mahood RJ, Curry KPW. Factors affecting the value of a simple biochemical scheme for identifying Enterobacteriaceae: the reproducible recognition of biotypes. J Clin Pathol 1977;30:495-504.

${ }^{8}$ Ørskov I, Ørskov F. Episome carried surface antigen K88 of Escherichia coli. J Bacteriol 1966;91:69-75.

${ }^{9}$ Casewell MW, Phillips I. Epidemiological patterns of Klebsiella colonisation and infection in an Intensive Care Ward. J Hyg Camb 1978;80:295-300.

${ }^{10}$ Casewell MW, Talsania HG. Predominance of certain Klebsiella capsular types in hospitals in the United Kingdom. J Infect 1979;1:77-9.

Requests for reprints to: Dr JG Barr, Department of Bacteriology, Royal Victoria Hospital, Grosvenor Road, N Belfast BT12 6BA. 